\title{
The efficacy of immunomodulators in the prevention and suppression of anti-drug antibodies to anti-tumor necrosis factor therapy in inflammatory bowel disease
}

\author{
Fotios S. Fousekis ${ }^{a}$, Konstantinos Papamichael ${ }^{b}$, Georgios Kourtisc, Eleni N. Albani ${ }^{d}$, Afroditi Orfanidou ${ }^{e}$, \\ Maria Saridi', Konstantinos H. Katsanos ${ }^{\text {a }}$, Dimitrios K. Christodoulou ${ }^{a}$ \\ School of Health Sciences, University Hospital of Ioannina, Faculty of Medicine, University of \\ Ioannina, Ioannina, Greece; Beth Israel Deaconess Medical Center, Harvard Medical School, Boston, Massachusetts, \\ USA; "Sotiria" General Hospital, Athens, Greece; Laiko General Hospital, Medical School of National and Kapodistrian \\ University of Athens, Greece; University of Patras, Greece; University of Patra, Greece; University of Thessaly, Greece
}

\begin{abstract}
The development of biological agents against tumor necrosis factor (TNF) has revolutionized the management of inflammatorybowel disease (IBD), frequently achieving induction and maintenance of remission in both ulcerative colitis and Crohn's disease. However, a loss of response due to the development of anti-drug antibodies (ADA) is seen annually in approximately $20 \%$ of IBD patients receiving anti-TNF therapy. Current evidence suggests that the use of immunomodulators (IMM), such as thiopurines (azathioprine and 6-mercaptopurine) or methotrexate, may prevent or suppress ADA formation. In this article, we present a comprehensive review of the available literature regarding the efficacy of IMM in the prevention and suppression of ADA development to anti-TNF therapy in patients with IBD.
\end{abstract}

Keywords anti-TNF, anti-drug antibodies, inflammatory bowel disease, thiopurines, methotrexate

Ann Gastroenterol 2021; 34 (1): 1-7

a'Department of Gastroenterology, School of Health Sciences, University Hospital of Ioannina, Faculty of Medicine, University of Ioannina, Ioannina, Greece (Fotios S. Fousekis,

Konstantinos H. Katsanos, Dimitrios K. Christodoulou); ${ }^{\text {bCenter for }}$ Inflammatory Bowel Diseases, Division of Gastroenterology, Beth Israel Deaconess Medical Center, Harvard Medical School, Boston, Massachusetts, USA (Konstantinos Papamichael); 'Department of Department of Nursing, "Sotiria" General Hospital, Athens, Greece (Georgios Kourtis); ${ }^{\mathrm{d}}$ Department of Nursing, University of Patra, Patra, Greece (Eleni N. Albani); ${ }^{\mathrm{e} A c a d e m i c ~ D e p a r t m e n t ~ o f ~ G a s t r o e n t e r o l o g y, ~}$ Laiko General Hospital, Medical School of National Kapodistrian University of Athens, Greece (Afroditi Orfanidou); ${ }^{\mathrm{f}}$ Department of Nursing, University of Thessaly, Lamia, Greece (Maria Saridi)

Conflict of interest: Konstantinos Papamichael reports lecture fees from Mitsubishi Tanabe Pharma and Physicians Education Resource LLC; consultancy fee from Prometheus Laboratories Inc; and scientific advisory board fees from ProciseDx Inc. and Scipher Medicine Corporation. The remaining authors declare no conflict of interest

Correspondence to: Dimitrios K. Christodoulou, MD, PhD, FEBGH, Professor of Gastroenterology, Department of Gastroenterology and Hepatology, School of Health Sciences, University Hospital of Ioannina, Faculty of Medicine, University of Ioannina, PO Box 1186, Ioannina 45110, Greece, e-mail: dchristodoulou@gmail.com

Received 29 July 2021; accepted 28 October 2021; published online 6 December 2021

DOI: https://doi.org/10.20524/aog.2021.0682

\section{Introduction}

The use of biological agents that target tumor necrosis factor (TNF) has revolutionized the treatment of inflammatory bowel disease (IBD), offering induction and maintenance of disease remission for both Crohn's disease (CD) and ulcerative colitis (UC). Currently, there are 4 approved anti-TNF agents against IBD: infliximab, adalimumab, golimumab, and certolizumab pegol. Infliximab is a chimeric monoclonal anti-TNF antibody, while adalimumab is a humanized monoclonal antibody, and they can be used in both UC and CD. On the other hand, certolizumab pegol, a polyethylene glycol-conjugated Fab fragment of recombinant humanized monoclonal antibody, has been approved to treat only $\mathrm{CD}$, while golimumab, a human anti-TNF IgG1, has been approved as a treatment for UC [1].

However, a significant proportion of IBD patients on anti-TNF treatment show a loss of response (LOR), requiring either dose intensification or switching to a different anti-TNF agent, or to an agent with a different mechanism of action. According to a metaanalysis, the estimated annual risk of LOR to anti-TNF agents is $20.9 \%$ per patient-year and the mean percentage of patients who lose response to infliximab, adalimumab and certolizumab pegol is $37.8 \%, 35.4 \%$ and $43.3 \%$, respectively [2], while up to $40 \%$ of UC patients responding to golimumab will lose response 
over time [3]. LOR can be mostly explained by subtherapeutic drug concentrations due to pharmacokinetic issues and the development of anti-drug antibodies (ADA), so called immunogenicity [4]. ADA may reduce the efficacy of anti-TNF agents via neutralization of the biological agent or acceleration of drug clearance [5]. The latter can also be induced by increased body weight and a high inflammatory burden, characterized by low albumin levels and elevated C-reactive protein (CRP) levels [6,7]. A recent systematic review demonstrated that ADA development is more frequent in patients receiving infliximab, and that the incidence of ADA formation varies from $0-65.3 \%$. On the other hand, the incidence of ADA in patients receiving adalimumab, golimumab or certolizumab ranges between 0.3$38 \%, 0.4-2.9 \%$ and $3.3-25.3 \%$, respectively [8].

Current data suggest that the combination of biological agents with immunomodulators (IMM), such as thiopurines and methotrexate, may prevent (Table 1) [9-18] or reduce (Table 2)
[19-23] ADA development, leading to maintenance of remission. Azathioprine and 6-mercaptopurine are the most frequently used thiopurines in IBD and they are considered suitable for maintenance of remission for both UC and CD [24,25]. Furthermore, methotrexate, a folate antagonist, may be used alone or as a combination therapy for the maintenance of remission in patients with CD [26], while it does not seem to have any role in UC [27]. The purpose of this review is to present and analyze the role of IMM in the prevention and suppression of ADA development in patients with IBD receiving anti-TNF therapy.

\section{Literature search}

We performed an in-depth review of the literature in PubMed to identify articles about the use of thiopurines in

Table 1 Major studies regarding prevention of ADA to anti-TNF therapy using combination therapy with an IMM

\begin{tabular}{|c|c|c|c|c|c|}
\hline $\begin{array}{l}\text { Anti- } \\
\text { TNF } \\
\text { agent }\end{array}$ & Study design & $\begin{array}{l}\text { IBD } \\
\text { type }\end{array}$ & $\begin{array}{l}\text { Number of patients on monotherapy } \\
\text { or combination therapy with an IMM }\end{array}$ & $\begin{array}{l}\text { Outcomes } \\
\text { (follow up) }\end{array}$ & Study (year) \\
\hline IFX & Prospective & $\mathrm{CD}$ & $\begin{array}{l}\text { IFX, } n=366 \\
\text { IFX+MTX/THP, } n=587\end{array}$ & $\begin{array}{l}\text { HR: } 0.39 ; 95 \% \text { CI:0.32- } 0.46 \\
\text { for ADA on combo- } \\
\text { therapy }\end{array}$ & $\begin{array}{l}\text { Kennedy, et al (2019) } \\
{[9]}\end{array}$ \\
\hline IFX & Retrospective & $\begin{array}{l}\mathrm{CD} / \\
\mathrm{UC}\end{array}$ & $\begin{array}{l}\text { IFX, } \mathrm{n}=139 \\
\text { IFX+MTX/6-MP, } \mathrm{n}=84\end{array}$ & $\begin{array}{l}\text { ADA: } 20.1 \% \\
\text { ADA: } 9.5 \%\end{array}$ & Chi, et al (2018) [10] \\
\hline IFX & Retrospective & $\mathrm{CD}$ & $\begin{array}{l}\text { IFX, } \mathrm{n}=93 \\
\text { IFX+THP (past THP responders), } \\
\mathrm{n}=52 \\
\text { IFX+THP (past THP failures), } \mathrm{n}=34 \\
\text { IFX+THP (de-novo combination), } \\
\mathrm{n}=28\end{array}$ & $\begin{array}{l}\text { ADA: } 46.6 \%(1 \mathrm{y}) \\
\text { ADA: } 19.3 \%(1 \mathrm{y}) \\
\text { ADA: } 16.1 \%(1 \mathrm{y}) \\
\text { ADA: } 21.9 \%(1 \mathrm{y})\end{array}$ & $\begin{array}{l}\text { Bar-Yoseph, et al } \\
\text { (2017) [11] }\end{array}$ \\
\hline IFX & RCT & $\mathrm{CD}$ & $\begin{array}{l}\text { IFX, } n=63 \\
\text { IFX+MTX, } n=63\end{array}$ & $\begin{array}{l}\text { ADA: } 20 \%(w 50) \\
\text { ADA: } 4 \%(w 50)\end{array}$ & $\begin{array}{l}\text { Feagan, et al (2014) } \\
\text { [12] }\end{array}$ \\
\hline IFX & Prospective & $\mathrm{CD}$ & $\begin{array}{l}\text { IFX, } \mathrm{n}=59 \\
\text { AZA+IFX, } \mathrm{n}=65\end{array}$ & $\begin{array}{l}\text { ADA: } 71 \%(w 4) \\
\text { ADA: } 48 \%(w 4)\end{array}$ & $\begin{array}{l}\text { Vermeire, et al (2007) } \\
\text { [13] }\end{array}$ \\
\hline $\mathrm{ADM}$ & Prospective & $\mathrm{CD}$ & $\begin{array}{l}\mathrm{ADM}, \mathrm{n}=344 \\
\mathrm{ADM}+\mathrm{THP}, \mathrm{n}=311\end{array}$ & $\begin{array}{l}\text { HR: } 0.44 \text {; } 95 \% \text { CI: } 0.31- \\
0.64 \text { for ADA on combo- } \\
\text { therapy }\end{array}$ & $\begin{array}{l}\text { Kennedy, et al (2019) } \\
{[9]}\end{array}$ \\
\hline $\mathrm{ADM}$ & Retrospective & $\begin{array}{l}\mathrm{CD} / \\
\mathrm{UC}\end{array}$ & $\begin{array}{l}\mathrm{ADM}, \mathrm{n}=67 \\
\mathrm{ADM}+\mathrm{THP}, \mathrm{n}=31\end{array}$ & $\begin{array}{l}\text { ADA: } 28 \% \\
\text { ADA: } 26 \%\end{array}$ & $\begin{array}{l}\text { Holmstrom, et al } \\
\text { (2018) [14] }\end{array}$ \\
\hline $\mathrm{ADM}$ & RCT & $\mathrm{CD}$ & $\begin{array}{l}\mathrm{ADM}, \mathrm{n}=85 \\
\mathrm{ADM}+\mathrm{AZA}, \mathrm{n}=91\end{array}$ & $\begin{array}{l}\text { ADA: } 13.2 \%(\mathrm{w} 26) \\
\text { ADA: } 4 \%(\mathrm{w} 26)\end{array}$ & $\begin{array}{l}\text { Matsumoto, et al } \\
\text { (2016) [15] }\end{array}$ \\
\hline GOL & $\mathrm{RCT}$ & UC & $\begin{array}{l}\text { GOL, } n=719 \\
\text { GOL+THP/MTX, n=345 }\end{array}$ & $\begin{array}{l}\text { ADA: } 3.5 \%(w 54) \\
\text { ADA: } 1.5 \%(w 54)\end{array}$ & $\begin{array}{l}\text { Adedokun, et al (2017) } \\
\text { [16] }\end{array}$ \\
\hline $\mathrm{CZP}$ & RCT & $\mathrm{CD}$ & $\begin{array}{l}\text { CZPa }, n=94 \\
C Z P+I M M, n=55\end{array}$ & $\begin{array}{l}\text { ADA }^{\text {b }: ~} 78 \% \\
\text { ADA }^{\text {b }}: 19 \%\end{array}$ & $\begin{array}{l}\text { Sandborn, et al (2017) } \\
\text { [17] }\end{array}$ \\
\hline $\mathrm{CZP}$ & RCT & $\mathrm{CD}$ & $\begin{array}{l}\text { CZP (for 6w), } n=407 \\
\text { CZP+MTX/6-MP (for 6w), n=261 } \\
\text { CZP (for 26w), n=126 } \\
\text { CZP+MTX/6-MP (for } 26 w \text { ), n=87 }\end{array}$ & $\begin{array}{l}\text { ADA: } 1 \%(w 6) \\
\text { ADA: } 0 \%(w 6) \\
\text { ADA: } 12 \%(w 26) \\
\text { ADA: } 2 \%(w 26)\end{array}$ & $\begin{array}{l}\text { Schreiber, et al (2007) } \\
{[18]}\end{array}$ \\
\hline
\end{tabular}

${ }^{\mathrm{a}}$ Without IMM for $\geq 90$ days, ${ }^{\mathrm{b}}$ Persistent ADA

ADA, anti-drug antibodies; RCT, randomized controlled trial; CD, Crohn's disease; UC, ulcerative colitis; IFX, infliximab; ADM, adalimumab; GOL, golimumab; CZP, certolizumab pegol; AZA, azathioprine; IMM, immunomodulators; MTX, methotrexate; 6-MP, 6-mercaptopurine; THP, thiopurines; HR, hazard ratio; w, week; $y$, year 
Table 2 Studies regarding suppression of ADA to anti-TNF therapy using combination therapy with an IMM

\begin{tabular}{|c|c|c|c|c|c|}
\hline Anti-TNF agent & Study design & IBD type & $\begin{array}{l}\text { No. of patients } \\
\text { (IMM) }\end{array}$ & Outcomes & Study (year) \\
\hline IFX & Retrospective & $\mathrm{CD}$ & $\mathrm{n}=13,(\mathrm{AZA})$ & $\begin{array}{l}\text { Decrease of ADA levels, [mean, } \\
(\mathrm{IQR})],[320(200-600) \text { to } 60(10- \\
500)(\mathrm{P}=0.01)] \text { and elevation of } \\
\text { IFX concentration }[0.015(0.01- \\
0.02) \text { to } 0.9(0.01-2.7) \mu \mathrm{g} / \mathrm{mL} \\
(\mathrm{P}=0.01)] . \text { Clinical remission was } \\
\text { achieved in } 54 \% \text { of patients }\end{array}$ & $\begin{array}{l}\text { Peyrin-Biroulet, } \\
\text { et al (2016) [19] }\end{array}$ \\
\hline IFX & Retrospective & $\mathrm{CD} / \mathrm{UC}$ & $\begin{array}{l}\mathrm{n}=5,(\mathrm{THP} / \\
\mathrm{MTX})\end{array}$ & $\begin{array}{l}\text { Suppression of ADA levels, } \\
\text { elevation of IFX trough } \\
\text { concentrations and restoration of } \\
\text { clinical response in all patients }\end{array}$ & $\begin{array}{l}\text { Ben-Horin, et al } \\
\text { (2013) [20] }\end{array}$ \\
\hline $\mathrm{ADM}$ & Retrospective & $\mathrm{CD} / \mathrm{UC}$ & $\begin{array}{l}\mathrm{n}=23 \text {, (THP/ } \\
\text { MTX) }\end{array}$ & $\begin{array}{l}48 \% \text { of patients achieved } \\
\text { elimination of ADA }\end{array}$ & $\begin{array}{l}\text { Ungar, et al } \\
\text { (2017) [21] }\end{array}$ \\
\hline IFX/ADM & Retrospective & $\mathrm{CD}$ & $\begin{array}{l}\mathrm{n}=30,(\mathrm{AZA} / \\
\text { MTX) }\end{array}$ & $\begin{array}{l}\text { 87\% decrease of median ADA } \\
\text { levels }\end{array}$ & $\begin{array}{l}\text { Colman, et al } \\
\text { (2021) [22] }\end{array}$ \\
\hline IFX/ADM & Retrospective & $\mathrm{CD} / \mathrm{UC}$ & $\begin{array}{l}\mathrm{n}=17(\mathrm{THP} / \\
\mathrm{MTX})\end{array}$ & $\begin{array}{l}76 \% \text { of patients achieved } \\
\text { undetectable ADA }\end{array}$ & $\begin{array}{l}\text { Strik, et al } \\
\text { (2017) [23] }\end{array}$ \\
\hline
\end{tabular}

ADA, anti-drug antibodies; $C D$, Crohn's disease; UC, ulcerative colitis; IFX, infliximab; $A D M$, adalimumab; AZA, azathioprine; MTX, methotrexate; 6-MP, 6-Mercaptopurine; THP, thiopurines; IQR, interquartile range; IMM, immunomodulator

the prevention and suppression of ADA in IBD, using the following search string: ("thiopurines" OR "azathioprine" OR "6-mercaptopurine" OR "methotrexate") AND ("antidrug antibodies") AND ("inflammatory bowel disease") AND ("anti-TNF” OR “infliximab” OR "adalimumab" OR "certolizumab pegol" OR "golimumab"). The references of relevant papers were also checked, while only articles in English were reviewed.

\section{Prevention of ADA to anti-TNF therapy}

Several studies have suggested that using either thiopurines or methotrexate in IBD patients on anti-TNF therapy may prevent ADA formation (Table 1) [9-18]. The concomitant use of thiopurines seems to contribute to the prevention of ADA development in patients treated with infliximab. In a multicenter cohort study, the prevalence of ADA was lower in the group of patients on combination therapy (infliximab plus azathioprine) compared to patients receiving infliximab monotherapy (46\% vs. $73 \%$; $\mathrm{P}<0.001$ ) [13]. Regarding the impact of azathioprine dose on immunogenicity, a retrospective study including patients with IBD receiving either infliximab or adalimumab combination therapy with azathioprine-group 1 (dose of azathioprine $<1 \mathrm{mg} / \mathrm{kg}$ ), group 2 (dose of azathioprine $\geq 1$ and $<2 \mathrm{mg} / \mathrm{kg}$ ), and group 3 (dose of azathioprine $\geq 2 \mathrm{mg} / \mathrm{kg}$ ) - found that there were no differences in trough concentrations, ADA, CRP and fecal calprotectin among the groups [28]. Along similar lines, a randomized clinical trial (RCT) demonstrated that the reduction in azathioprine dosage from $2-2.5 \mathrm{mg} / \mathrm{kg} /$ day to $1-1.25 \mathrm{mg} / \mathrm{kg} /$ day did not significantly affect infliximab trough concentrations and ADA development [29]. The same study showed that the optimal 6-thioguanine (6-TGN) level to predict unfavorable IFX pharmacokinetics was $<105$ $\mathrm{pmol} / 8.10^{8}$ red blood count (RBC). Consequently, it seems that the effect of azathioprine on ADA development and infliximab trough concentrations may not be dose-dependent, at least when 6-TGN levels are $\geq 105 \mathrm{pmol} / 8.10^{8} \mathrm{RBC}$.

Besides thiopurines, methotrexate may also prevent the development of ADA against infliximab. A double-blind, placebo-controlled RCT demonstrated that CD patients on combination therapy compared to those receiving infliximab monotherapy had a lower risk of ADA development (4\% vs. $20 \%, \mathrm{P}=0.01$ ) and higher median serum trough infliximab concentrations $(6.35 \mathrm{mg} / \mathrm{mL}$ vs. $3.75 \mathrm{mg} / \mathrm{mL}, \mathrm{P}=0.08)$ [12]. Moreover, the prospective PANTS (Personalising Anti-TNF Therapy in Crohn's Disease) study found that infliximab combination therapy with an IMM (methotrexate or thiopurines) decreased the risk of developing ADA (hazard ratio $[\mathrm{HR}]$ 0.39, 95\% confidence interval [CI] 0.32-0.46; $\mathrm{P}<0.001$ ) [9]. In a cross-sectional analysis of 233 pediatric and young adult patients with IBD, those receiving combination therapy of infliximab with 6-mercaptopurine or methotrexate compared to those receiving infliximab alone had a lower rate (9.5\% vs. $20 \%$, respectively) and a lower risk of detectable ADA (odds ratio [OR] $0.3,95 \% \mathrm{CI} 0.1-0.7 ; \mathrm{P}<0.01$ ). In addition, patients on combination therapy had higher infliximab concentrations than those on infliximab monotherapy $(17.00 \pm 1.33 \mu \mathrm{g} / \mathrm{mL}$ vs. $13.18 \pm 1.26 \mu \mathrm{g} / \mathrm{mL} ; \mathrm{P}<0.001)$ [10].

In contrast to infliximab, there are conflicting data regarding the use of thiopurines in IBD patients on adalimumab and their efficacy in increasing adalimumab serum concentrations, prevention of ADA and improvement of clinical outcomes [30]. A multicenter, open-labeled RCT showed that there was only a trend towards a lower rate of ADA formation in patients on adalimumab combination therapy with azathioprine compared to adalimumab monotherapy at week 26 ( $4 \%$ vs. $13 \%$; $\mathrm{P}=0.078$ ), while clinical efficacy and adalimumab trough concentrations 
were similar between the 2 groups [15]. A meta-analysis demonstrated that combination adalimumab therapy with azathioprine is associated with less ADA formation (OR 0.24, 95\%CI $0.07-0.82 ; \mathrm{P}=0.02$ ), although there was no statistically significant difference between combination therapy and monotherapy regarding the induction and maintenance of remission [31]. A recent study analyzing the interaction between thiopurine metabolites, adalimumab and ADA in previously infliximab-treated IBD patients, demonstrated that combination therapy is not associated with prevention of ADA, and that the levels of thiopurine metabolites are not associated with ADA development [14]. However, the prospective PANTS study found that adalimumab combination therapy with IMM (methotrexate or thiopurines) reduced the risk of developing ADA (HR 0.44, 95\%CI 0.31-0.64; $\mathrm{P}<0.001$ ) [9]. In one RCT, IBD patients in corticosteroid-free clinical remission for at least 6 months on adalimumab and thiopurines were randomized into 2 subgroups: withdrawal or continuation of thiopurines. After 52 weeks, there was no statistically significant difference in ADA positivity between the 2 groups ( $20 \%$ vs. $10 \%$, respectively; $\mathrm{P}=0.437$ ) [32].

In contrast to infliximab and adalimumab, there are limited data regarding the impact of IMM on the development of ADA against certolizumab pegol and golimumab. An analysis of results from the phase $2 / 3$ PURSUIT RCTs demonstrated only a numerically lower incidence of ADA against golimumab in patients receiving golimumab and IMM compared to those on golimumab monotherapy (1.5\% vs. $3.5 \%)$ [16]. A population PK model, using data from the PURSUIT (Program of Ulcerative Colitis Research Studies Utilizing an Investigational Treatment) RCTs, showed that anti-golimumab antibodies increased drug clearance by $24.3 \%$ and that the impact of ADAs on golimumab concentration was more notable at higher ADA levels ( $\geq 1: 100$ ) [34]. One RCT demonstrated that the incidence of ADA was lower in patients receiving certolizumab and IMM compared to certolizumab monotherapy during both induction ( $0 \%$ vs. $1 \%)$ and maintenance therapy (2\% vs. $12 \%)$ [18].

\section{Prevention of ADA in patients with prior anti-TNF failure due to immunogenicity}

It is worth mentioning that IBD patients with ADA to a prior anti-TNF agent seem to be more likely to develop ADA to a subsequent anti-TNF [35-37]. A recent retrospective casecontrol study including 5828 patients with IBD showed that patients who developed ADA to infliximab and switched from infliximab to adalimumab had a higher risk of developing ADA against adalimumab (OR 2.82, 95\%CI 2.35-3.38; $\mathrm{P}<0.001$ ). The same applied for patients who developed ADA to adalimumab and had to switch from adalimumab to infliximab: they had a higher risk of developing ADA against infliximab (HR 3.43, 95\%CI 2.81-4.2; $\mathrm{P}<0.001$ ) [35]. One RCT showed that the addition of azathioprine to the switch of anti-TNF agent in patients with IBD in clinical relapse with undetectable anti-TNF trough concentrations and ADA is associated with lower rates of clinical failure compared to anti-TNF monotherapy [36]. In addition, combination therapy decreased the pharmacokinetic failure significantly (undetectable trough concentrations of infliximab or adalimumab and high ADA levels) compared to anti-TNF monotherapy (adalimumab and azathioprine: HR 0.12, 95\% CI 0.03-0.40; $\mathrm{P}<0.001$; infliximab and azathioprine: $\mathrm{HR}$ $0.16,95 \%$ CI $0.06-0.37 ; \mathrm{P}<0.001$ ) [36]. Thus, it is recommended to add an IMM to a subsequent anti-TNF therapy when considering switching within drug class in case of LOR to a first anti-TNF agent due to immunogenicity [37].

\section{Suppression of ADA to anti-TNF therapy}

As mentioned above, LOR to anti-TNF therapy due to immunogenicity is a frequent issue of IBD management and switching to another agent appears to be a common strategy. However, treatment optimization (dose escalation and/or addition of an IMM) can also be an option in case of low-titer $\mathrm{ADA}$, as current data suggest that these can be suppressed or even eliminated, leading to elevation of serum anti-TNF trough concentrations, restoration of clinical response and salvage of the current anti-TNF biological agent [38-40]. Preliminary data suggest that the addition of an IMM may contribute to $\mathrm{ADA}$ suppression and recapture of anti-TNF response (Table 2) [19-23]. In 2013, a retrospective analysis of IBD patients documented for the first time that the administration of IMM in 5 IBD patients with LOR and ADA against infliximab was associated with suppression of ADA levels, elevation of infliximab trough concentrations and restoration of clinical response in all patients. Three of 5 patients received thiopurines and 2 patients received methotrexate [20]. Similarly, another retrospective study demonstrated the suppression of ADA in IBD patients with LOR to infliximab or adalimumab after the addition of IMM [23]. Six of 10 patients on anti-TNF monotherapy receiving thiopurine and all (7/7) patients receiving methotrexate achieved clinical remission, undetectable ADA and elevation of drug concentrations [23]. A recent retrospective study, which included pediatric IBD patients with ADA against adalimumab or infliximab, reported that addition of an IMM is associated with suppression of ADA, an increased likelihood of steroid-free clinical remission and anti-TNF durability [22]. In this study, patients on combination therapy exhibited an $87 \%$ decrease in ADA levels and a median increase of $7.2 \mu \mathrm{g} / \mathrm{mL}$ of anti-TNF drug concentrations [22]. Furthermore, in another multicenter retrospective study, 14 IBD patients on adalimumab monotherapy, LOR and ADA development received thiopurine as salvage therapy. Restoration of clinical response and elimination of ADA were achieved in half of the patients. The median time to sero-reversal was 5 months [21].

Thus, the addition of IMM in IBD patients with ADA to infliximab or adalimumab and undetectable or sub-therapeutic drug concentrations appears to be an effective strategy to overcome immunogenicity before switching to another agent. However, a limitation of the aforementioned studies is the very small sample size and the retrospective design. Moreover, data regarding the role of IMM for suppression or elimination of ADA in IBD patients receiving golimumab or certolizumab pegol are missing. 


\section{Biosimilars}

Current data suggest that infliximab and adalimumab biosimilars share immunodominant epitopes and exhibit similar immunogenicity with the originators [41-43]. Switching from infliximab originator to biosimilar, both single and multiple switches, does not seem to raise any efficacy and safety issues or immunogenicity concerns $[44,45]$. However, due to cross-immunogenicity, switching from an originator to a biosimilar or vice versa when the one or the other fails due to ADA formation should not be recommended [46,47].

\section{Mechanisms of IMM to prevent or suppress immunogenicity of anti-TNF therapy}

The mechanisms of action of IMM to prevent or suppress immunogenicity of anti-TNF agents have not been fully clarified. It has been suggested that methotrexate and thiopurines may reduce $\mathrm{T}$-cell proliferation and cause attenuation of memory $\mathrm{B}$ cell and CD-4 T cells, reducing anti-TNF immunogenicity and eliminating ADA formation $[48,49]$. However, further studies are warranted.

\section{Discussion}

Despite extensive research into the treatment of IBD, treatment options remain relatively limited, at least for some IBD phenotypes, such as perianal fistulizing $\mathrm{CD}$ and acute severe UC, where infliximab is the cornerstone treatment. Thus, also taking into account the chronicity of the disease, it may be prudent to try to maintain the initially used biologic before switching to an alternative therapy.
In recent years, measurement of drug concentrations and ADA levels, so called therapeutic drug monitoring (TDM), has contributed to efficiently optimizing anti-TNF therapy. Several medical societies and TDM expert groups recommend reactive TDM to better explain the cause of lack or loss of response, while some also suggest proactive TDM with dose adaptation to a target drug concentration in patients with quiescent disease at post-induction, and at least once during maintenance therapy, to improve the efficacy of anti-TNFs [50]. Regarding reactive TDM, Yanai et al showed that patients with LOR and no or low-titer ADA compared to those with high-titer ADA against adalimumab $(>4 \mu \mathrm{g} / \mathrm{mL})$ or infliximab $(>9 \mu \mathrm{g} / \mathrm{mL})$ had a longer duration of response following dose intensification [51]. Regarding proactive TDM, a large retrospective study found that proactive TDM compared to empiric dose optimization and/or reactive TDM of infliximab was associated with better therapeutic outcomes, including a lower risk of ADA development [52]. TDM, with emphasis on measuring ADA, should also be performed after reinitiation of infliximab following a drug holiday, as ADA developed early (1-3 weeks) after re-exposure to infliximab has been associated with (severe) infusion reactions [53,54].

The concomitant use of IMM seems to be an effective strategy for the prevention and suppression of ADA against anti-TNF therapy and can lead to higher drug concentrations and better therapeutic outcomes. The mechanisms underlying the favorable impact of IMM on clinical outcomes are still not well understood. Besides their positive impact on anti-TNF drug pharmacokinetics, it may be also an "add-on" effect, although in a post hoc analysis of the SONIC (Study of Biologic and Immunomodulator Naïve Patients in Crohn's Disease) RCT, stratification of infliximab concentrations displayed comparable outcomes within each concentration quartile, irrespective of concomitant azathioprine [55].

However, there may be safety concerns regarding combination therapy, including an increased risk of infections and

Table 3 Possible risks of anti-TNF combination therapy with an IMM in IBD

\begin{tabular}{|c|c|c|c|c|}
\hline Outcome & Study design & Drug type & $\begin{array}{l}\text { Risk of anti-TNF combo- } \\
\text { therapy with an } \text { IMM }^{a}\end{array}$ & Study (year) \\
\hline Serious infection & $\begin{array}{l}\text { Retrospective } \\
\text { Meta-analysis (12 } \\
\text { RCTs) }\end{array}$ & $\begin{array}{l}\text { IFX/ADM } \\
\text { IFX/ADM }\end{array}$ & $\begin{array}{l}\text { HR:1.23; 95\%CI:1.05-1.45 } \\
\text { RR:1.20; 95\%CI:0.83-1.73 }\end{array}$ & $\begin{array}{l}\text { Kirchgesner, et al (2018) [56] } \\
\text { Chen, et al (2021) [57] }\end{array}$ \\
\hline $\begin{array}{l}\text { Opportunistic } \\
\text { infection }\end{array}$ & $\begin{array}{l}\text { Retrospective } \\
\text { Meta-analysis ( } 12 \\
\text { RCTs) }\end{array}$ & $\begin{array}{l}\text { IFX/ADM } \\
\text { IFX/ADM }\end{array}$ & $\begin{array}{l}\text { HR:1.96; 95\%CI:1.32-2.91 } \\
\text { RR:1.13; 95\%CI:0.94-1.36 }\end{array}$ & $\begin{array}{l}\text { Kirchgesner, et al (2018) [56] } \\
\text { Chen, et al (2021) [57] }\end{array}$ \\
\hline Tuberculosis & $\begin{array}{l}\text { Systematic review } \\
(40 \text { RCTs })^{\mathrm{b}}\end{array}$ & $\begin{array}{l}\text { IFX/ADM/ } \\
\mathrm{CZP}\end{array}$ & OR:13.3; 95\%CI:3.7-100 & Lorenzetti, et al (2014) [58] \\
\hline COVID-19 & Retrospective & $\begin{array}{l}\text { IFX/ADM/ } \\
\mathrm{CZP} / \mathrm{GOL}\end{array}$ & aOR:4.01; 95\%CI:1.65-9.78 & Ungaro, et al (2021) [59] \\
\hline Lymphoma & Retrospective & IFX/ADM & aHR:6.11; 95\%CI:3.46-10.8 & Lemaitre, et al (2017) [60] \\
\hline NMSC & Meta-analysis (6 RCTs) ${ }^{c}$ & $\mathrm{ADM}$ & RR:2.82; 95\%CI:1.07-7.44 & Osterman, et al (2013) [61] \\
\hline $\begin{array}{l}\text { Malignancies } \\
\text { other than NMSC }\end{array}$ & Meta-analysis $(6 \mathrm{RCTs})^{c}$ & $\mathrm{ADM}$ & RR:3.46, 95\%CI:1.08-11.06 & Osterman, et al (2013) [61] \\
\hline
\end{tabular}

${ }^{\mathrm{a}}$ Thiopurines/methotrexate; ${ }^{\mathrm{b}}$ Including also rheumatologic diseases; ${ }^{\mathrm{c} C r o h n ' s ~ d i s e a s e ~}$

IBD, inflammatory bowel disease; Ahr, adjusted Hazard ratio; NMSC, non-melanoma skin cancer; aOR, adjusted odds ratio; CI, confidence interval; RR, relative risk; RCT, randomized clinical trial; TNF, tumor necrosis factor; IMM, immunomodulator; IFX, infliximab; ADM, adalimumab; CZP, certolizumab pegol; GOL, golimumab 
malignancies [56-61] (Table 3). Consequently, an individualized risk-benefit assessment based on disease severity and extent, history of prior anti-TNF failure, the pharmacokinetic profile, and possibly the patient's genetic background, should be considered for determining the optimal therapy. Regarding the latter, a genome-wide association study of the PANTS study showed that the HLA-DQA $1^{*} 05$ allele increased the risk of development of ADA against infliximab and adalimumab, and that this was attenuated by the use of a concomitant IMM [62].

\section{Concluding remarks}

Current data suggest that IMM can prevent immunogenicity against anti-TNF therapy, leading to improved drug pharmacokinetics and therapeutic outcomes. In addition, preliminary data suggest that IMM can reduce or eliminate ADA against infliximab or adalimumab in patients with IBD and immunogenicity issues. However, given the safety concerns of combination therapy, an individualized riskbenefit assessment is essential for defining the most suitable treatment for each patient.

\section{References}

1. D'Haens GR, van Deventer S. 25 years of anti-TNF treatment for inflammatory bowel disease: lessons from the past and a look to the future. Gut 2021;70:1396-1405.

2. Qiu Y, Chen BL, Mao R, et al. Systematic review with meta-analysis: loss of response and requirement of anti-TNF $\alpha$ dose intensification in Crohn's disease. J Gastroenterol 2017;52:535-554.

3. Strik AS, Berends SE, Mathôt RA, D’Haens GR, Löwenberg M. Golimumab for moderate to severe ulcerative colitis. Expert Rev Gastroenterol Hepatol 2017;11:401-406.

4. Fine S, Papamichael K, Cheifetz AS. Etiology and management of lack or loss of response to anti-tumor necrosis factor therapy in patients with inflammatory bowel disease. Gastroenterol Hepatol (N Y) 2019;15:656-665.

5. van der Laken CJ, Voskuyl AE, Roos JC, et al. Imaging and serum analysis of immune complex formation of radiolabelled infliximab and anti-infliximab in responders and non-responders to therapy for rheumatoid arthritis. Ann Rheum Dis 2007;66:253-256.

6. Berends SE, Strik AS, Löwenberg M, D’Haens GR, Mathôt RAA. Clinical pharmacokinetic and pharmacodynamic considerations in the treatment of ulcerative colitis. Clin Pharmacokinet 2019;58:15-37.

7. Brandse JF, van den Brink GR, Wildenberg ME, et al. Loss of infliximab into feces is associated with lack of response to therapy in patients with severe ulcerative colitis. Gastroenterology 2015;149:350-355.e2.

8. Vermeire S, Gils A, Accossato P, Lula S, Marren A. Immunogenicity of biologics in inflammatory bowel disease. Therap $A d v$ Gastroenterol 2018;11:1756283X75035.

9. Kennedy NA, Heap GA, Green HD, et al; UK Inflammatory Bowel Disease Pharmacogenetics Study Group. Predictors of anti-TNF treatment failure in anti-TNF-naive patients with active luminal Crohn's disease: a prospective, multicentre, cohort study. Lancet Gastroenterol Hepatol 2019;4:341-353.

10. Chi LY, Zitomersky NL, Liu E, et al. The impact of combination therapy on infliximab levels and antibodies in children and young adults with inflammatory bowel disease. Inflamm Bowel Dis 2018;24:1344-1351.
11. Bar-Yoseph H, Waterman M, Almog R, et al. Prevention of antidrug antibody formation to infliximab in Crohn's patients with prior failure of thiopurines. Clin Gastroenterol Hepatol 2017;15:69-75.

12. Feagan BG, McDonald JW, Panaccione R, et al. Methotrexate in combination with infliximab is no more effective than infliximab alone in patients with Crohn's disease. Gastroenterology 2014;146:681-688.

13. Vermeire S, Noman M, Van Assche G, Baert F, D'Haens G, Rutgeerts P. Effectiveness of concomitant immunosuppressive therapy in suppressing the formation of antibodies to infliximab in Crohn's disease. Gut 2007;56:1226-1231.

14. Holmstrøm RB, Mogensen DV, Brynskov J, et al. Interactions between thiopurine metabolites, adalimumab, and antibodies against adalimumab in previously infliximab-treated patients with inflammatory bowel disease. Dig Dis Sci 2018;63:1583-1591.

15. Matsumoto T, Motoya S, Watanabe K, et al. Adalimumab monotherapy and a combination with azathioprine for Crohn's disease: a prospective, randomized trial. J Crohns Colitis 2016;10:1259-1266.

16. Adedokun OJ, Xu Z, Marano CW, et al. Pharmacokinetics and exposure-response relationship of golimumab in patients with moderately-to-severely active ulcerative colitis: Results from Phase 2/3 PURSUIT induction and maintenance studies. J Crohn's Colitis 2017;11:35-46.

17. Sandborn WJ, Wolf DC, Kosutic G, et al. Effects of transient and persistent anti-drug antibodies to certolizumab pegol: longitudinal data from a 7-year study in Crohn's disease. Inflamm Bowel Dis 2017;23:1047-1056.

18. Schreiber S, Khaliq-Kareemi M, Lawrance IC, et al. Maintenance therapy with certolizumab pegol for Crohn's disease. $N$ Engl J Med 2007;357:239-250.

19. Peyrin-Biroulet L, Salleron J, Filippi J, et al. Anti-TNF monotherapy for Crohn's disease: a 13-year multicentre experience. J Crohns Colitis 2016;10:516-524.

20. Ben-Horin S, Waterman M, Kopylov U, et al. Addition of an immunomodulator to infliximab therapy eliminates antidrug antibodies in serum and restores clinical response of patients with inflammatory bowel disease. Clin Gastroenterol Hepatol 2013;11:444-447.

21. Ungar B, Kopylov U, Engel T, et al. Addition of an immunomodulator can reverse antibody formation and loss of response in patients treated with adalimumab. Aliment Pharmacol Ther 2017;45:276-282.

22. Colman RJ, Portocarrero-Castillo A, Chona D, Hellmann J, Minar P, Rosen MJ. Favorable outcomes and anti-TNF durability after addition of an immunomodulator for anti-drug antibodies in pediatric IBD patients. Inflamm Bowel Dis 2021;27:507-515.

23. Strik AS, van den Brink GR, Ponsioen C, Mathot R, Löwenberg M, D'Haens GR. Suppression of anti-drug antibodies to infliximab or adalimumab with the addition of an immunomodulator in patients with inflammatory bowel disease. Aliment Pharmacol Ther 2017;45:1128-1134.

24. Goel RM, Blaker P, Mentzer A, Fong SC, Marinaki AM, Sanderson JD. Optimizing the use of thiopurines in inflammatory bowel disease. Ther Adv Chronic Dis 2015;6:138-146.

25. Chaparro M, Gisbert JP. Maintenance therapy options for ulcerative colitis. Expert Opin Pharmacother 2016;17:1339-1349.

26. Herfarth $\mathrm{HH}$, Kappelman MD, Long MD, Isaacs KL. Use of methotrexate in the treatment of inflammatory bowel diseases. Inflamm Bowel Dis 2016;22:224-233.

27. Carbonnel F, Colombel JF, Filippi J, et al; Groupe d'Étude Thérapeutique des Affections Inflammatoires Digestives. Methotrexate is not superior to placebo for inducing steroid-free remission, but induces steroid-free clinical remission in a larger proportion of patients with ulcerative colitis. Gastroenterology 2016;150:380-388.e4.

28. Arieira C, Dias Castro, Cúrdia G T, Moreira MJ, Cotter J. 
Combination therapy in inflammatory bowel disease patients: do we need to maximize the dose of azathioprine? Scand $J$ Gastroenterol 2020;55:920-923.

29. Roblin X, Boschetti G, Williet N, et al. Azathioprine dose reduction in inflammatory bowel disease patients on combination therapy: an open-label, prospective and randomised clinical trial. Aliment Pharmacol Ther 2017;46:142-149.

30. Löwenberg M. Is there a beneficial effect of adding azathioprine to adalimumab in Crohn's disease patients? Ann Transl Med 2018;6:278.

31. Chalhoub JM, Rimmani HH, Gumaste VV, Sharara AI. Systematic review and meta-analysis: adalimumab monotherapy versus combination therapy with immunomodulators for induction and maintenance of remission and response in patients with Crohn's disease. Inflamm Bowel Dis 2017;23:1316-1327.

32. Hisamatsu T, Kato S, Kunisaki R, et al; DIAMOND2 Study Group. Withdrawal of thiopurines in Crohn's disease treated with scheduled adalimumab maintenance: a prospective randomised clinical trial (DIAMOND2). J Gastroenterol 2019;54:860-870.

33. Adedokun OJ, Xu Z, Liao S, et al. Population pharmacokinetics and exposure-response modeling of golimumab in adults with moderately to severely active ulcerative colitis. Clin Ther 2020;42:157-174.

34. Vande Casteele N, Abreu MT, Flier S, et al. Patients with low drug levels or antibodies to a prior anti-tumor necrosis factor are more likely to develop antibodies to a subsequent anti-tumor necrosis factor. Clin Gastroenterol Hepatol 2021 Jan 6 [Online ahead of print]. doi: 10.1016/j.cgh.2021.01.006

35. Roblin X, Williet N, Boschetti G, et al. Addition of azathioprine to the switch of anti-TNF in patients with IBD in clinical relapse with undetectable anti-TNF trough levels and antidrug antibodies: a prospective randomised trial. Gut 2020;69:1206-1212.

36. Cheifetz AS, Abreu MT, Afif W, et al. A comprehensive literature review and expert consensus statement on therapeutic drug monitoring of biologics in inflammatory bowel disease. Am J Gastroenterol 2021;116:2014-2025.

37. Cohen RZ, Schoen BT, Kugathasan S, Sauer CG. Management of anti-drug antibodies to biologic medications in children with inflammatory bowel disease. J Pediatr Gastroenterol Nutr 2019;69:551-556.

38. Ong DE, Kamm MA, Hartono JL, Lust M. Addition of thiopurines can recapture response in patients with Crohn's disease who have lost response to anti-tumor necrosis factor monotherapy. J Gastroenterol Hepatol 2013;28:1595-1599.

39. Papamichael K, Vajravelu RK, Osterman MT, Cheifetz AS. Long-term outcome of infliximab optimization for overcoming immunogenicity in patients with inflammatory bowel disease. Dig Dis Sci 2018;63:761-767.

40. Fiorino G, Begoña Ruiz-Argüello MB, Maguregui A, et al. Full interchangeability in regard to immunogenicity between the infliximab reference biologic and biosimilars CT-P13 and SB2 in inflammatory bowel disease. Inflamm Bowel Dis 2018;24:601-606.

41. Hanauer S, Liedert B, Balser S, Brockstedt E, Moschetti V, Schreiber S. Safety and efficacy of BI 695501 versus adalimumab reference product in patients with advanced Crohn's disease (VOLTAIRE-CD): a multicentre, randomised, double-blind, phase 3 trial. Lancet Gastroenterol Hepatol 2021;6:816-825.

42. Jørgensen KK, Goll GL, Sexton J, et al. Efficacy and safety of CTP13 in inflammatory bowel disease after switching from originator infliximab: exploratory analyses from the NOR-SWITCH main and extension trials. BioDrugs 2020;34:681-694.

43. Macaluso FS, Cummings JF, Atreya R, Choi J, Orlando A. A systematic review on infliximab biosimilar sb2: from pre-clinical data to real-world evidence. Expert Opin Biol Ther 2021 Jul 27 [Online ahead of print]. doi: 10.1080/14712598.2021.1958778
44. Fischer S, Cohnen S, Klenske E, et al. Long-term effectiveness, safety and immunogenicity of the biosimilar SB2 in inflammatory bowel disease patients after switching from originator infliximab. Therap Adv Gastroenterol 2021;14:1756284820982802.

45. Ben-Horin S, Yavzori M, Benhar I, et al. Cross-immunogenicity: antibodies to infliximab in Remicade-treated patients with IBD similarly recognise the biosimilar Remsima. Gut 2016;65:11321138.

46. Goncalves J, Myung G, Park M, Jeong D, Ghil J. SB5 shows crossimmunogenicity to adalimumab but not infliximab: results in patients with inflammatory bowel disease or rheumatoid arthritis. Therap Adv Gastroenterol 2019;12:175628481989108.

47. Ben-Horin S, Ungar B, Roblin X. Letter: can addition of an immunomodulator really reverse antibody formation and loss of response in patients treated with adalimumab? Authors' reply. Aliment Pharmacol Ther 2017;45:760-762.

48. Strand V, Goncalves J, Isaacs JD. Immunogenicity of biologic agents in rheumatology. Nat Rev Rheumatol 2021;17:81-97.

49. Papamichael K, Cheifetz AS. Therapeutic drug monitoring in patients on biologics: lessons from gastroenterology. Curr Opin Rheumatol 2020;32:371-379.

50. Yanai H, Lichtenstein L, Assa A, et al. Levels of drug and antidrug antibodies are associated with outcome of interventions after loss of response to infliximab or adalimumab. Clin Gastroenterol Hepatol 2015;13:522-530.

51. Papamichael K, Chachu KA, Vajravelu RK, et al. Improved longterm outcomes of patients with inflammatory bowel disease receiving proactive compared with reactive monitoring of serum concentrations of infliximab. Clin Gastroenterol Hepatol 2017; 15:1580-1588.

52. Baert F, Drobne D, Gils A, et al. Early trough levels and antibodies to infliximab predict safety and success of reinitiation of infliximab therapy. Clin Gastroenterol Hepatol 2014;12:1474-1481.e2.

53. Normatov I, Fluxa D, Wang JD, et al. Real world experience with proactive therapeutic drug monitoring during infliximab reintroduction. Crohns Colitis 360 2021;3:otab048.

54. Colombel JF, Adedokun OJ, Gasink C, et al. Combination therapy with infliximab and azathioprine improves infliximab pharmacokinetic features and efficacy: a post hoc analysis. Clin Gastroenterol Hepatol 2019;17:1525-1532.

55. Kirchgesner J, Lemaitre M, Carrat F, Zureik M, Carbonnel F, DraySpira R. Risk of serious and opportunistic infections associated with treatment of inflammatory bowel diseases. Gastroenterology 2018;155:337-346.

56. Chen L, Xu CJ, Wu W, Ding BJ, Liu ZJ. Anti-TNF and immunosuppressive combination therapy is preferential to inducing clinical remission in patients with active inflammatory bowel disease: A systemic review and meta-analysis. J Dig Dis 2021;22:408-418.

57. Lorenzetti R, Zullo A, Ridola L, et al. Higher risk of tuberculosis reactivation when anti-TNF is combined with immunosuppressive agents: a systematic review of randomized controlled trials. Ann Med 2014;46:547-554.

58. Ungaro RC, Brenner EJ, Gearry RB, et al. Effect of IBD medications on COVID-19 outcomes: results from an international registry. Gut 2021;70:725-732.

59. Lemaitre M, Kirchgesner J, Rudnichi A, et al. Association between use of thiopurines or tumor necrosis factor antagonists alone or in combination and risk of lymphoma in patients with inflammatory bowel disease. JAMA 2017;318:1679-1686.

60. Osterman MT, Sandborn WJ, Colombel JF, et al. Increased risk of malignancy with adalimumab combination therapy, compared with monotherapy, for Crohn's disease. Gastroenterology 2014;146:941-949.

61. Sazonovs A, Kennedy NA, Moutsianas L, et al; PANTS Consortium. HLA-DQA ${ }^{*} 05$ carriage associated with development of anti-drug antibodies to infliximab and adalimumab in patients with Crohn's disease. Gastroenterology 2020;158:189-199. 